\title{
Ambassadors, friends and family join charitable walk to honour Anoop Maini
}

More than 120 people from the world of dentistry took part in a sponsored walk on 15 September to raise money for the Wells on Wheels charity - and to honour dentist Anoop Maini, who tragically passed away in July.

The charity provides a rolling solution to water carriers in India. Participants walked two miles around the boating lake in Regent's Park in London, each carrying heavy bottles of water, in a bid to experience what carrying water in rural Indian villages might feel like.

Organised by dental marketing expert Shaz Memon, the event added to funds already raised, bringing it to a total of $£ 27,000$ - and the money will pay for water drums on wheels to be delivered to rural India.

These drums are designed to ease the burden on the many women who risk their health daily carrying heavy buckets of water on their heads to their communities.

Wells on Wheels ambassadors, dentists Shiraz Khan and Nilesh Parmar, joined 'Singing Dentist' Milad Shadrooh and TV presenter and radio host, Lizzie Cundy.

Among those at the event were Anoop's family as well as some of his patients.

Speaking about the event, Shaz Memon said: 'This walk was a tribute to Anoop's legacy and was also a great way to create awareness as well as raise funds for those women who deserve an easier life supplying their communities with water.

'I'd like to thank all those volunteers who gave up their time to help, everyone who attended to raise the much-needed funds for Wells on Wheels and especially the Maini family for supporting the cause. A

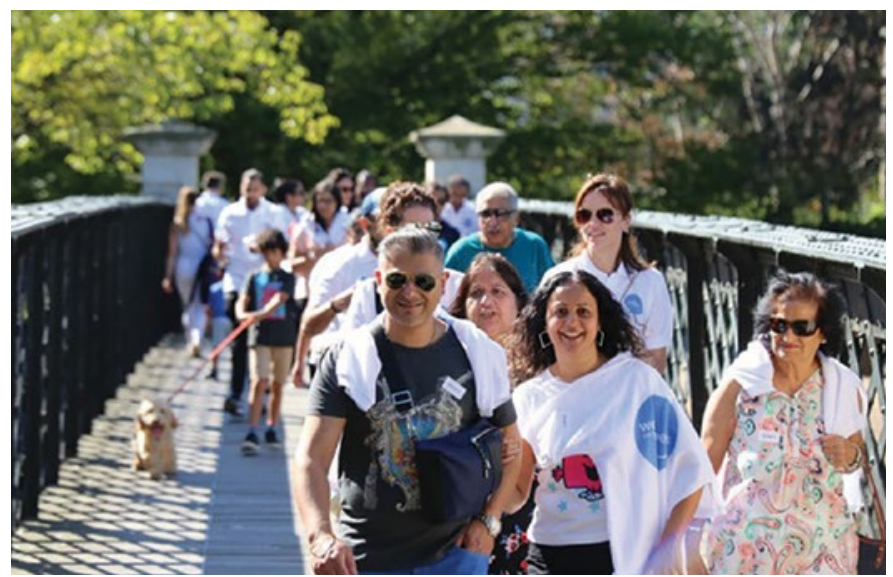

The sponsored walk in Regent's Park, London

big thank you to Rishi Tibrewal, from TURI events, for his organisation skills.'

Thanks to the walkers who participated, Wells on Wheels will purchase 100 wheels, with a further 400 planned.

For more information, visit https://www.wellsonwheels.co.uk/.

News of the sudden death of Dr Maini - widely considered a pioneer in cosmetic dentistry - shook the dental world back in July. Highly skilled in implant dentistry and orthodontics, Anoop was Past President of the British Association of Cosmetic Dentistry (BACD) and the European Society of Aesthetic Orthodontics (ESAO), and Vice President of the Board of Directors for the BACD. He also lectured internationally and was highly respected within the industry.

\section{John Zamet Memorial Prize applications open}

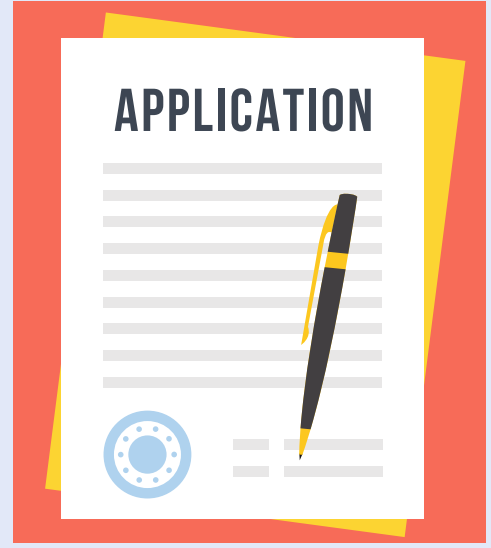

The John Zamet Memorial Prize in Periodontal Research, offered in association with the Alpha Omega London Chapter and Charitable Trust, has been established to recognise and commemorate the significant contribution made to clinical periodontology by the late Dr John Zamet.

Dr Zamet was an Honorary Consultant and Senior Research Fellow at the UCL Eastman Dental Institute, a Past President and Honorary Member of the British Society of Periodontology and the founder Chairman and a Trustee of the Alpha Omega London Chapter and Charitable Trust.

Applications are open to all UK-based postgraduate dental students studying for a Master's degree or $\mathrm{PhD}$ who are undertaking or who have recently completed original research associated with clinical periodontology.

The prize is awarded biennially with a value of $£ 2,000$.

Applicants should submit a covering letter and an abstract not exceeding 1,000 words which should, at least, cover the following areas: 1 . Background to project; 2 . Aims; 3 . Methods; 4 . Relevance to clinical periodontology; and 5. Start and completion dates (estimated completion date will suffice if ongoing).

Three paper copies of the application should be submitted by 31 December 2019 to Professor Andrew Eder, Chairman, The Alpha Omega London Charitable Trust, 2nd floor, 57a Wimpole Street, London W1G 8YP. They should also be sent electronically via email to: andreweder@restorative-dentistry.co.uk.

The applicant must also submit a letter of support from their research supervisor confirming their supervision of the project.

The submission will be considered by a panel of at least two Specialists in Periodontology whose decision is final.

The successful applicant would normally be invited to present the results and/or clinical implications of the research at a meeting of the Alpha Omega London Chapter. 